\title{
Economía social y empleo. El caso de España ${ }^{*}$
}

\section{Fausto Miguélez}

Universitat Autònoma de Barcelona. Departament de Sociologia

08193 Bellaterra (Barcelona). Spain

fausto.miguelez@uab.es

\section{Resumen}

Este artículo analiza la realidad del tercer sector o economía social, posicionado entre el público y el privado, con particular atención a la naturaleza de sus empresas. Seguidamente, estudia su capacidad de crear empleo, así como las características del mismo, preguntándose por el papel que puede desempeñar en la redefinición del Estado de bienestar.

Palabras clave: economía social, tercer sector, empleo, bienestar.

\section{Abstract. Social Economy and Employment. The Spanish Case}

This article makes an analysis of the so called third sector (or social economy) because of its position between the private sector and the state. Some special attention is paid to the characteristics of the companies working in the sector. Afterwards arguments move on the aptittude of the third sector to create jobs and on the discussion over the place the social economy might have in a redifined Welfare State.

Key words: social econony, third sector, employment, welfare.

\section{Sumario}

1. Introducción al problema

2. Crisis del Estado de bienestar e insuficiencia del mercado

3. La economía social puede crear empleo

4. Contra el riesgo de "guetización» del empleo en el tercer sector
5. ¿Regular las relaciones laborales en el tercer sector?

6. Conclusión: economía social y bienestar

Bibliografía

* Este artículo fue presentado en forma de ponencia en las jornadas sobre Economía del tercer sector, organizadas por PROGEA en la Universidad de Zaragoza el 3 de junio de 2004. 


\section{Introducción al problema}

Hace veinticinco años, la tasa de salarización de la mayoría de los países de la Unión Europea era muy elevada y seguía creciendo, la situación era de pleno empleo, la mayoría de los empleos estaban en el ámbito privado, seguidos por aquéllos del ámbito público. Los empleos asalariados fuera de estos dos ámbitos, principalmente en las cooperativas, eran pocos, sobresaliendo países como Noruega e Italia, aunque también se daban en Francia, España y en otros. En aquel momento, se podía hablar de decrecimiento de los ocupados en ese sector intermedio o tercer sector que no era estrictamente el mercado, pero tampoco el sector público, debido al papel desempeñado por el Estado en el bienestar y en el empleo. Hoy, por el contrario, se registra un fuerte crecimiento del tercer sector, que también se denomina economía social. Éste es el gran cambio.

\subsection{La cuestión que se plantea}

Analizar la relación entre economía social y empleo obliga a delimitar los dos términos con claridad teórica y práctica. Y ése es el primer problema con el que nos encontramos al hablar de economía social. Economía social, tercer sector, tercer sistema tienen significados diferentes según la historia de ese ámbito, según las legislaciones y según el papel que en él desempeña el Estado en cada país. Tradicionalmente, existían las cooperativas (agrarias, de producción, de consumo, de vivienda). El nombre de economía social se populariza en Francia después de la Segunda Guerra Mundial (aunque ya se había utilizado a principios de siglo) para subrayar una orientación no lucrativa, sino social, y tal nombre luego es adaptado en otros países. En realidad, ciertos elementos de la economía social, como las mencionadas cooperativas, ya aparecen en el siglo XIX como una primera reacción al capitalismo y sus limitaciones. También España tiene una rica tradición histórica de asociacionismo y cooperativismo que se ve truncada por la dictadura y el papel absorbente del Estado, y que sólo reemprende en los últimos años del franquismo y luego en la democracia. En realidad, el cooperativismo moderno y el asociacionismo laboral tiene también esa característica: son organizaciones que incorporan finalidades sociales y colectivas (el empleo, el consumo), normalmente buscan una cierta colaboración con el Estado y ponen el énfasis en la democracia económica. Economía social implica, en el fondo, reciprocidad y compromiso con problemas colectivos, por tanto, tiene que ver con la cohesión social.

Pero la terminología puede ser engañosa. La tradición americana ha llamado tercer sector a todas aquellas entidades no lucrativas que tienen como característica que todos los beneficios se han de reinvertir en la actividad, porque, aunque son privadas, generan positividades de interés general. En la concepción americana entrarían organizaciones que no son habituales en lo que nosotros llamamos economía social, como clubes deportivos o asociaciones profesionales, sindicatos, partidos. En algunos de estos casos, la actividad puede 
generar grandes beneficios, aunque éstos no sean medibles con el patrón de las empresas. También cabe ser críticos con la etiqueta de "no lucrativo», puesto que eso puede ocultar grandes desigualdades jerárquicas y de remuneración dentro de esas empresas, o que a veces funcionan «en beneficio» de un número reducido de personas (Gomá y otros, 2001). Pero, sobre todo, porque si estas entidades no son lucrativas - otra cosa es lo que hacen con el lucro obtenido-, difícilmente podrán competir en el mercado con otras empresas, porque no se ve cómo pueden invertir en tecnología y en nuevos métodos. Veremos luego que uno de los problemas de muchas cooperativas de trabajo asociado (CTA) es justamente que no tienen lucro.

La Unión Europea introduce otra denominación en 1997, «tercer sistema", al analizar el potencial ocupacional derivado de necesidades insatisfechas a las que no responden ni el mercado ni el sector público, sino los llamados «nuevos yacimientos de empleo». La Unión no entra en las formas jurídicas, sino que enfatiza la novedad de las formas sociales y económicas como participación y desarrollo local inherentes a estas actividades.

A los efectos que aquí nos interesan, creo conveniente diferenciar los apartados siguientes dentro del tercer sector, la economía social o tercer sistema:

1. Cooperativas: se basan en que la gestión la llevan los socios y la propiedad es de ellos mismos: su objetivo puede ser la producción (agrícola, industrial, servicios), el consumo y el trabajo asociado.

2. Sociedades anónimas laborales (SAL): igualmente basadas en la autogestión de los socios trabajadores, siendo su objetivo el empleo de los mismos a través de la producción o los servicios.

3. Fundaciones, asociaciones y ONG, las diferencias internas en este inmenso apartado pueden ser muy grandes: las ONG basadas en el voluntariado, con pocos socios empleados, nada tienen que ver con las fundaciones de las cajas o de equipos de fútbol, ni con la Organización Nacional de Ciegos ni con las asociaciones de vecinos.

A sabiendas de la limitación, y para evitar la complejidad del punto 3, voy a centrarme principalmente en las dos primeras, subrayando que la autogestión es su característica principal, y en tal sentido son empresas privadas, es decir, de aquéllos que las gestionan, y que pueden estar en el mercado compitiendo con cualquier otro tipo de empresas privadas $y$, por tanto, tener beneficios y reinvertirlos.

\subsection{Los términos del problema}

¿Hasta qué punto se está incrementando en los últimos veinte años un espacio de actividad diferenciado entre los dos ámbitos tradicionales, el sector público y el sector privado tradicional, que justamente por esa posición recibe el nombre de "tercer sector", y hasta qué punto se convierte en un motor relevante en la actividad económica y en la creación de empleo? El núcleo del pro- 
blema está, pues, en analizar el empleo de ese sector intermedio, en el bien entendido de que, en el llamado «modelo europeo de bienestar y cohesión social», el empleo ha desempeñado un papel primordial. La crisis del empleo, en sus aspectos tanto cuantitativos como cualitativos, parece poner en riesgo aquel modelo, pues sería menos sostenido por el mercado (por razones de competitividad) y no estaría garantizado para todos por el Estado (por razones de orientación menos intervencionista y/o crisis fiscal). El tercer sector entraría a desempeñar ahí un papel, en buena medida debido a que esta no presencia directa del Estado no impide que haya una actuación indirecta, bien contratando servicios que se prestan a los ciudadanos por ese tipo de empresas, bien apoyando normativamente o financieramente ciertas formas de empleo en las mismas. Por tal razón, el tercer sector no es equidistante entre los otros dos, sino que puede estar más cercano al sector público y que, efectivamente, lo está según ciertos expertos (Gomá y otros, 2001).

\section{Crisis del Estado de bienestar e insuficiencia del mercado}

En la base del llamado «modelo de sociedad del bienestar», hay crecimiento económico, por supuesto. Pero también hay un pacto social de distribución de la riqueza creada en modo que se garanticen unos recursos razonables para todos. El canal principal de distribución de la misma es el empleo. Por ello, el empleo no es dejado al mero resultado del mercado, de la contraposición de oferta y demanda, sino que está regulado por la sociedad, en un doble sentido: se garantiza que haya empleo para todo aquél que quiera trabajar, y se garantiza que ese empleo tenga unas condiciones adecuadas. Será empleo con reglas, como dicen ciertos autores (Prieto, 2002). Bienestar equivale a situación de estabilidad objetiva y de seguridad subjetiva. En buena medida, en los años sesenta y setenta, esa estabilidad y seguridad provienen del importante crecimiento que tiene el empleo público en el Estado de bienestar, completada la función creadora de empleo del sector privado.

La seguridad en el empleo significa que el contrato estable es la norma y que la mayoría de la población está empleada en trabajos de larga duración. Dicho contrato fijo suele estar protegido por indemnizaciones contra posible despido y por seguro de desempleo contra la pérdida del mismo. Así mismo, quiere decir que la gran mayoría son empleos a tiempo completo, siendo los empleos a tiempo parcial una opción voluntaria del trabajador, que, de esa manera, puede asumir otro tipo de actividades que tiene que llevar a cabo o que desea realizar; también en la duración de la jornada, la seguridad es una pauta a la que los trabajadores se pueden acoger, más los hombres que las mujeres. Pero a medida que la tasa de actividad de éstas últimas empieza a incrementarse, en particular en los países del centro y del norte de Europa, los empleos que pueden encontrar las mujeres son principalmente a tiempo parcial. Que la mayoría de ellas afirme que ése es el tipo de empleo que desean (Comisión Européenne, 2003), no basta para entender que tienen las mismas oportunidades que los hombres. Por tanto, no habría que olvidar que estamos 
hablando de una norma social del empleo básicamente masculina, de una sociedad que piensa en el empleo en términos de garantía del mismo para el cabeza de familia hombre.

Pero quizá el aspecto más importante sea la garantía de esta estabilidad en el empleo, es decir, el hecho de que las personas sepan que, más allá de sus cualidades, de sus esfuerzos y de sus influencias personales, pueden esperar que la sociedad les ayudará a mantener el puesto de trabajo. Ello ha sido así no sólo por la existencia de ciertas leyes y normas, sino también porque, de facto, se han creado dinámicas sociales que van en esa dirección: estrategias de sindicatos, negociación, pactos, políticas públicas, etc.

¿Por qué ahora se habla de crisis del empleo? No se trata sólo de la dificultad para obtener empleo, es decir, de la amenaza del paro. Si bien el paro no es ahora tan dramático en la UE como hace diez años (excepción hecha de un par de países de la_Unión), el temor a que pueda volver a subir constituye un importante factor de presión sobre el empleo que empuja a éste a la inestabilidad, la cual se convierte así en la verdadera cuestión de fondo de la crisis del empleo. Esa inestabilidad tiene variantes según países, pero sus consecuencias, aunque diversas en gravedad, son las mismas en todos los países: inseguridad, vulnerabilidad, menor protección, riesgo de exclusión o exclusión propiamente dicha. La inestabilidad del empleo se traduce, o corre el riesgo de traducirse, en inestabilidad de las condiciones de vida y de bienestar.

¿Cuáles son las causas de este profundo cambio? En el periodo de la gran expansión económica de los países centrales, las empresas tenían asegurados el mercado interior y el mercado exterior, que eran relativamente estables, aunque obviamente con competencia entre empresas. El acceso a la tecnología también era estable. Respecto al tercer factor, el trabajo, se había tejido una red de negociaciones y regulaciones - es la sustancia del pacto social, el otro factor de gran trascendencia-, las cuales permitían despejar razonablemente su incertidumbre de comportamiento para las empresas, con repercusiones positivas para éstas y para los trabajadores. Esto había dado a los representantes del trabajo una importante cuota de poder. El cambio radica en que el nuevo panorama económico - que podríamos sintetizar en el fenómeno de la globalización y en la menor intervención del Estado- ha incrementado las incertidumbres respecto al factor tecnología y al factor mercado, incertidumbres que ya no pueden ser despejadas a nivel interior de cada país, ni siquiera con apoyo del Estado, al menos en la mayoría de los países. Los mercados internos tampoco son tan estables, ni siquiera con el apoyo del Estado. Para poder competir, las empresas han ido variando su estrategia de manera que puedan controlar, cada vez más en exclusiva, el tercer factor, el trabajo, consiguiendo, a través de la flexibilidad, que sea éste el que asuma gran parte de las incertidumbres en solitario. La incertidumbre para los trabajadores es el significado profundo de la flexibilización del empleo (Pollert, 1991).

La consecuencia de esta crisis es que el mercado no está garantizando el pleno empleo, puesto que, aún después de los descensos del desempleo del 
último decenio, tenemos una tasa de paro en la Unión del 8\% (10\% en España, en 2004), ni está garantizando un empleo con mínimos de estabilidad y de futuro. Pero el Estado tampoco llena tal vacío, pues no sólo crea poco empleo público, sino que una parte del que crea es precario (CES, 2005). Pero, además, en toda la Unión y en todos los países desarrollados, han descendido los apoyos y las subvenciones colectivas al bienestar: ha disminuido la cobertura del desempleo, se incrementa la base de cálculo de cotización de la jubilación, con lo que ésta tiende a disminuir, se incrementan los costes privados de la sanidad y disminuyen los recursos dedicados a las llamadas "políticas sociales». Por tanto, no se dibuja un substituto del empleo como instrumento de bienestar.

Aquí es donde aparece la economía social (ES) o tercer sector, que podría desempeñar un papel clave para garantizar el empleo a quienes no pueden lograrlo en los otros dos ámbitos o bien para cubrir con servicios, y por tanto con empleos - más allá de las actividades del voluntariado y la solidaridad-, la aparición de nuevas necesidades individuales y colectivas. En la ES se podría plantear una flexibilidad laboral, pero con garantías sociales debido a la naturaleza económica y jurídica de esas empresas. Por ello, mantengo una doble tesis: que el bienestar tiene que seguir basándose de manera prioritaria en el trabajo, transformado en empleo, y que el tercer sector puede desempeñar en ello un papel importante, a condición de garantizar empleo de calidad.

\section{La economía social puede crear empleo}

En los inicios de la década actual, se calcula que unos 700.000 empleados en España lo están en la economía social (CESB, 2002). En ciertas regiones, el porcentaje será notable: Catalunya, Andalucía. La economía social, que hace varias décadas era un fenómeno fuerte en ámbitos rurales o semirurales (Italia), se ha convertido ahora en un fenómeno mucho más urbano. Las posibilidades de creación de empleo hoy día por parte de la economía social parecen muy importantes (Vidal, 2001).

\subsection{Nuevas necesidades y nuevos empleos}

Cuando nos preguntamos sobre el porqué del enorme crecimiento de la economía social en los últimos veinticinco años, nos percatamos que la razón está en la aparición de nuevas necesidades que mucha gente considera que deberían estar universalmente cubiertas. A ellas, por supuesto, se suman las necesidades tradicionales. Estas necesidades son plausibles de traducirse en empleos.

Necesidad de garantizarse el propio empleo. Ante el fracaso del mercado y del Estado al respecto, muchas personas han visto en la ES una forma de buscar trabajo y bienestar. Aunque es obvio que estos trabajadores deberán tener los mismos derechos que los demás, no cabe olvidar que no estamos hablando de 
empleos estrictamente en los mismos términos que en el caso de los trabajadores asalariados.

Necesidades que tienen que ver con la calidad de vida. Gozar de buena salud, pero también evitar la soledad y el aislamiento o bien apoyo a las personas, sin que ello signifique que otras tienen que sacrificar sus posibilidades de plena realización personal. Eso tendría que significar la creación de una serie de servicios en los que la administración local ha de desempeñar un papel importante, aunque no necesariamente exclusivo. Aquí hemos de considerar principalmente los servicios a domicilio.

Necesidades que tienen que ver con un uso del tiempo más autónomo. Crecen las posibilidades de tener más tiempo liberado de la obligación de trabajar (en el mercado y en el ámbito doméstico). Dicho tiempo puede ser disputado por dos concepciones del bienestar: una consumista (usar ese tiempo para ganar más) y otra de disfrute de tiempo en sí mismo. En esa segunda concepción, se requieren nuevos servicios - y hasta reeducación para el ocio- en los que la Administración no tiene que desempeñar el papel sustantivo, es decir, garantizar los mismos, pero sí puede tener un papel organizador. Ello se traduce principalmente en dos cuestiones: facilitar la movilidad pública y avanzar en una nueva regulación de los tiempos de la ciudad, hoy fuertemente condicionados por el tiempo exclusivo de la producción industrial. Se dan repercusiones sobre los horarios de escuelas, de sanidad, de comercio, de ocio (Varios Autores, 2002). Aquí se ubica también la problemática de la conciliación entre la vida laboral y familiar (Torns, 2004).

Necesidades derivadas del respeto a la ecosfera para un mejor equilibrio entre ésta $y$ los humanos. El respeto al hábitat y a los ciclos naturales, la salvaguarda y moderación en el uso de los recursos, las políticas de ahorro y anticontaminadoras, pueden tener la máxima efectividad si es la comunidad y no el mercado quien protagoniza el proceso. Parece que es la comunidad a escala local quien tiene las máximas posibilidades de llegar a un desarrollo sostenible, puesto que es en el territorio concreto donde se produce y se consume, aunque sin olvidar las necesarias conexiones interterritoriales que el desarrollo sostenible debería tener.

Las nuevas oportunidades de empleo que se crean tienen que ver, por un lado, con esas nuevas necesidades expresadas y, por otro, con las nuevas políticas de empleo impulsadas por la UE.

Un paradigma completo de estas nuevas necesidades lo tenemos en los llamados "yacimientos de empleo». Son definidos como «actividades destinadas a satisfacer nuevas necesidades sociales, sean individuales o colectivas, que tienen una fuerte concentración territorial y de esa manera pueden ser satisfechas a través de un trabajo». En general, se trata de actividades en el ámbito de los servicios con una fuerte impronta local. Traducen potencialidades que 
hoy existen de lo que podríamos llamar «sociedad del bienestar local», que está ya permitiendo diferencias notables en términos de calidad de vida según territorios y localidades. Todos estos aspectos propician que los recursos materiales para los mismos deban ser en gran parte locales y que los recursos humanos presumiblemente también lo sean. Pero su desarrollo dependerá mucho de que existan esos recursos en el ámbito local.

Algunos autores (Cachón, 1998) han evaluado las necesidades de empleo que se podrían dar en España en los próximos años en nuevos yacimientos que serían, en teoría, muy importantes, sencillamente porque hasta ahora están escasamente cubiertas. Pero, evidentemente, se necesitan recursos para convertirlos en realidad. También han identificado los principales obstáculos y los instrumentos para su desarrollo. Entre los obstáculos, podemos mencionar los financieros, los de formación y cualificación, la burocracia, los culturales, la competencia de la economía informal. Entre los instrumentos, se podría contar con el "cheque servicios», con ciertas exenciones fiscales, con el ahorro de proximidad (banca ética y local) y con las políticas activas de empleo (con subvenciones de diverso tipo). Parece evidente que, si estamos hablando de una nueva intervención de la Administración y de diversas actuaciones de la sociedad civil en los nuevos yacimientos de empleo, el terreno está abonado para la ES, también porque la capitalización requerida en esas empresas con frecuencia es baja, siendo los recursos humanos mucho más importantes.

La Estrategia Europea para el Empleo (EES), desde Amsterdam (1997), nace sobre dos presupuestos. En el terreno institucional, la comisión se compromete a elaborar para cada año los grandes criterios de política de empleo que luego los estados adecuan en sus respectivos planes nacionales de actuación (NAP). En el terreno de las políticas, se diseñan cuatro pilares de actuación: a) mejorar la capacidad de inserción profesional; $b$ ) desarrollar el espíritu de empresa; $c$ ) fomentar la capacidad de adaptación, y $d$ ) reforzar la política de igualdad de oportunidades. Los pilares $a$ y, sobre todo, $b$ abren oportunidades a la economía social. En el primero, con las posibilidades de empleo subvencionado, en el segundo, fomentando el trabajo por cuenta propia y promoviendo la creación de empleo en la economía social local y en nuevas actividades, por ejemplo, a través de reducción de carga fiscal. Todo ello permite captar recursos del Fondo Social Europeo. En el gráfico 1, podemos ver esta distribución de recursos por países relativa a 2001. España está por encima de la UE-15, lo que quiere decir que hasta hora ha habido aquí posibilidades muy interesantes.

\subsection{El empleo en la economía social ¿motor de bienestar?}

Es difícil cuantificar el empleo de la economía social. Según las fuentes utilizadas, en el año 2002 oscilaba en España entre 600.000 y 800.000. La razón principal de la discrepancia puede estar en contar o no los autónomos, las fundaciones y otras empresas. Estamos por debajo de la mayoría de países de la Unión-15 y 

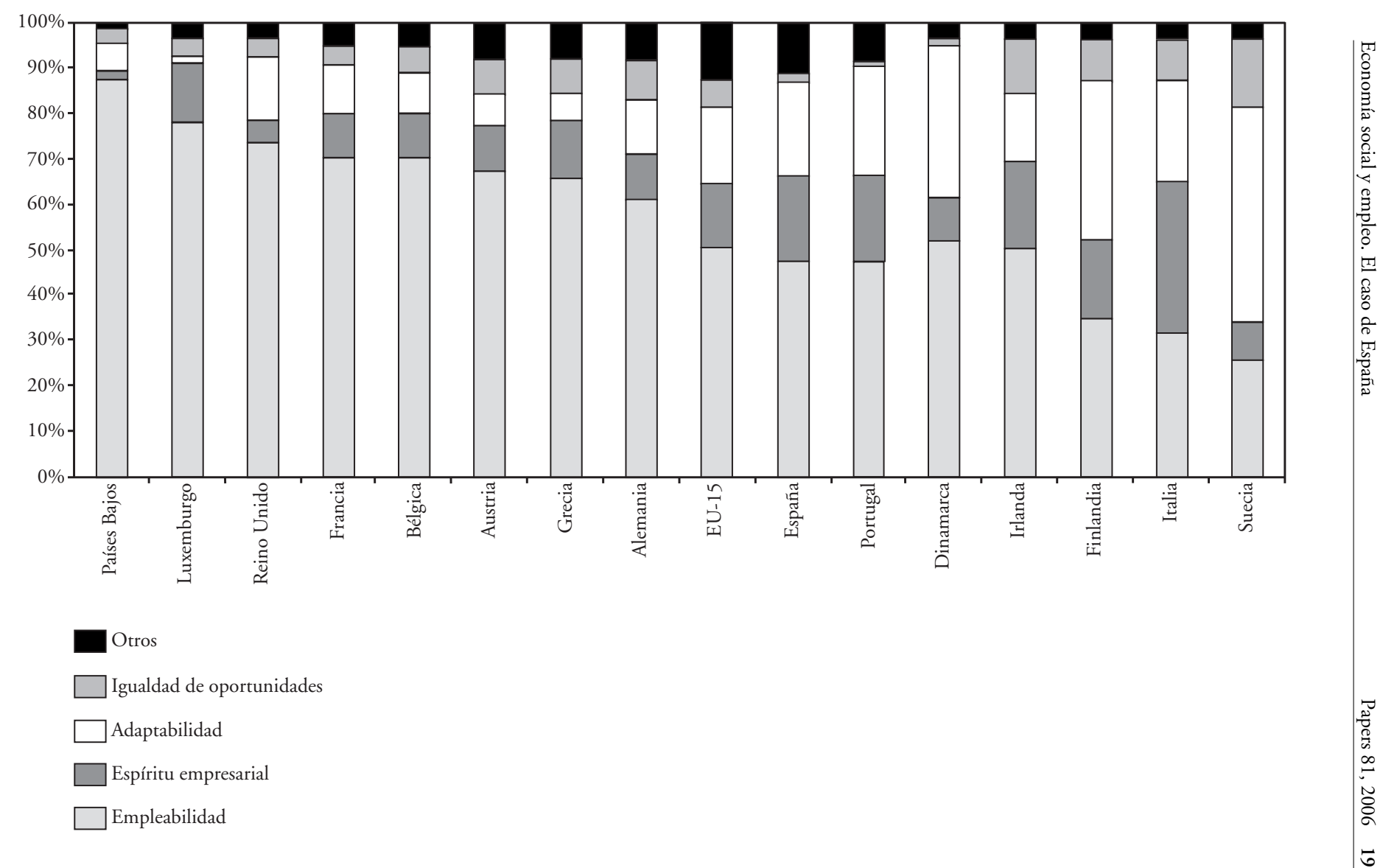

Gráfico 1. Gasto previsto del FSE con arreglo a los objetivos n. ${ }^{\circ} 1$ y 3, por pilares (2001). 
a mucha distancia de algunos como Holanda, Irlanda o Bélgica, que superan el $12 \%$.

Utilizando el trabajo de Barea y Monzón (2002) para CIRIEC, que se sitúa en la hipótesis más baja, tenemos la siguiente distribución:

- ONG de acción social (asociaciones y fundaciones): 215.307 (2000) ${ }^{1}$. - Cooperativas de trabajo asociado: 273.187 (2002) (contando socios y empleados).

- Sociedades laborales: 100.535 (2002).

- Resto de empresas de economía social (otras cooperativas): 107.556 (2000).

Considerando sólo las cooperativas y las sociedades laborales, aquellos ámbitos de la ES con mayor pujanza en la actualidad, dos terceras partes se concentran en Andalucía, País Vasco, Catalunya y Comunidad Valenciana. En términos relativos a su población activa, destacarían: Andalucía, Murcia, Comunidad Valenciana y Euskadi. Lo más significativo es que el empleo en la economía social está creciendo desde inicios de los años noventa en tasas superiores a las del empleo en la economía en su conjunto hasta 2002, lo que nos hace pensar que este segmento puede llegar a ser relevante, sobre todo si tenemos en cuenta cómo la descentralización y los autónomos se están incrementando en la UE. Por tal razón, aún más importante que saber cuánto empleo se genera es conocer las características del mismo, como veremos en el apartado siguiente.

Vamos a referirnos a los ámbitos de la ES, que pueden ser los más significativos en el momento actual por lo que respecta a su potencial presente y futuro en la creación de empleo: las cooperativas de trabajo asociado y las sociedades laborales, también a las empresas de inserción para el trabajo, que pueden adquirir una de esas modalidades o ser simplemente sociedades anónimas. El ámbito de las fundaciones puede amagar la presencia de empresas potentes que se benefician de ese estatuto.

Las cooperativas de trabajo asociado comienzan a desempeñar un papel, que cada año se incrementa, desde mediados de los ochenta, principalmente por la crisis del empleo y por los recursos públicos que se ponen en ellas. Da una idea de esto, echar un vistazo somero a su evolución: en 1960, las cooperativas eran 378 en España, en 1980 no llegaban a 900, en 2002 eran 17.649. Evidentemente, hoy desempeñan un papel frente a la crisis del empleo y en las políticas laborales. Pero el aumento ha sido impulsado por la cada vez más frecuente satisfacción de aquellas necesidades de nuevo tipo, particularmente las referidas a servicios a las personas, en las cuales el Estado y la sociedad deben tener un cierto papel sin que necesariamente tenga que ser hacerse cargo totalmente de ellas incluyéndolas en el ámbito público. El nuestro es un país de tradición cooperativa, aunque no tan fuerte como otros, pero, tradicional-

1. Sobre algunas fundaciones. es discutible que hayan de ser consideradas del tercer sector. 
mente, estas cooperativas se habían ubicado en el sector agrícola o el industrial o en el consumo. En el año 2000 no sólo están mayoritariamente en los servicios, sino que el número de CTA equivale al $70 \%$ del total de cooperativas, lo que demuestra la diferencia en el ritmo de crecimiento entre este tipo de cooperativas y las tradicionales.

Si analizamos los últimos siete años (gráfico 2), que reflejan las estadísticas de cotización a la Seguridad Social, podemos percibir un incremento paulatino de estas empresas, al menos hasta 2002 (el descenso de 2003 se puede deber en parte a un ajuste metodológico). El incremento de trabajadores es muy importante y prácticamente no ha cesado de crecer, con la excepción de la primera mitad de 2003. Considerado por sectores, el incremento afecta casi exclusivamente a los servicios, con la excepción de la agricultura en el año 2003. Así, en la construcción, la cifra de trabajadores se mantiene estable en unos 20.000. En la industria, hay asimismo estabilidad, en torno a los 70.000. En la agricultura, la cifra crece de 20.000 a 25.000 entre 1997 y 2002, para casi doblarse en 2003 (habría que analizar el porqué de este salto). Pero en los servicios, que ya cuenta con 120.000 en el primero de los años considerados, se llega a 180.000 en 2003. En realidad, las CTA desde principios de los noventa son un fenómeno principalmente de los servicios. Los subsectores en los

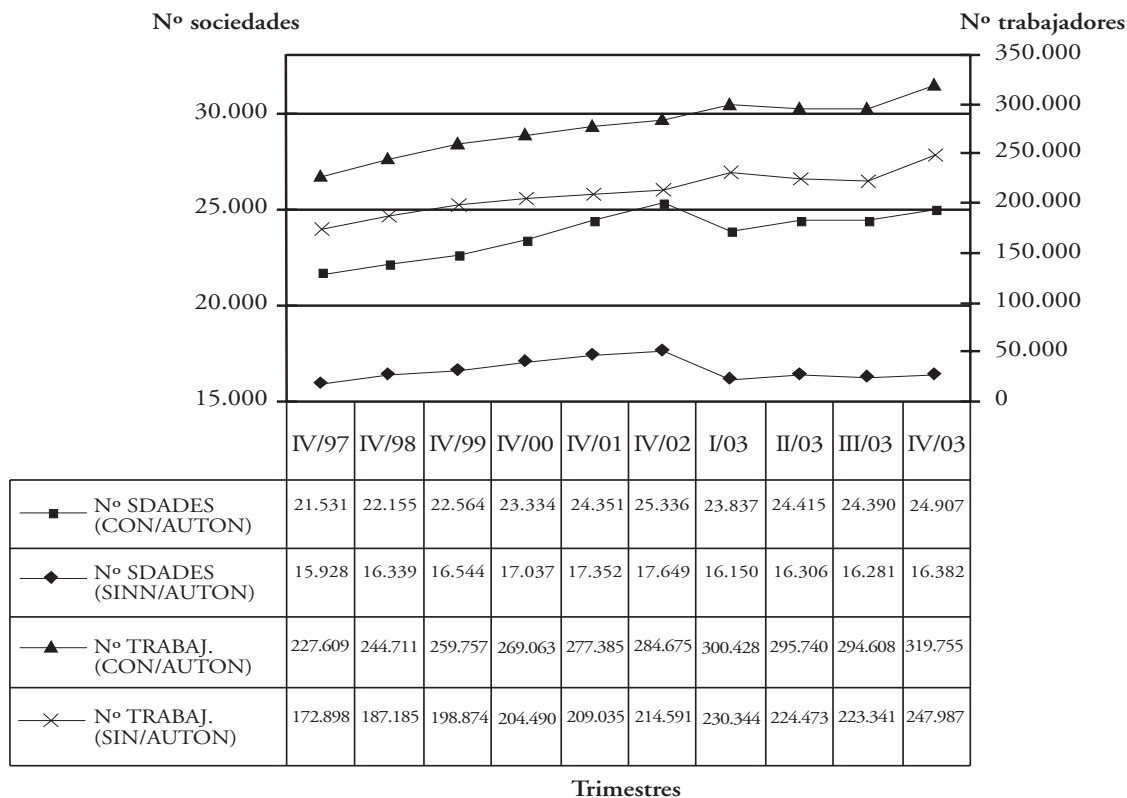

Gráfico 2. Sociedades cooperativas. Evolución del número de sociedades y de trabajadores. (Fuente: Ministerio de Trabajo y Seguridad Social) 
que se incrementan estas empresas son servicios personales (educativos, sanitarios, sociales y a las familias), comercio y hostelería, transporte, y servicios a las empresas. En varios de ellos, particularmente en los primeros, la inversión inicial necesaria es baja, mientras que la demanda, apoyada por la Administración, puede ser alta. Por otro lado, predomina la microempresa — más de la mitad no supera los cinco trabajadores-, lo que es un indicador de su volumen reducido de actividad, pero también de su escasa especialización y de debilidad ante coyunturas poco favorables, como pueden ser los recortes en políticas sociales relativas a los servicios que estas empresas desarrollan. Pero también existen empresas medianas y grandes, que son relevantes en términos de empleo: basta señalar que las empresas con cien trabajadores y más — que en 2000 son el 1,5\% - tienen el 30\% de la ocupación total. La relación entre CTA según tamaños puede ocasionar problemas de competitividad de una cierta envergadura con repercusiones sobre el empleo, como veremos luego. Las empresas grandes tienen más posibilidades de hacerse con los grandes contratos de servicios personales a nivel local, lo que debiera suscitar la exigencia de mayor asociación entre empresas pequeñas a efectos de competir en el mercado.

Finalmente, en una apreciación más sociológica, cabe decir que la CTA es hoy una empresa que ofrece servicios personales en zonas urbanas, algo obvio dada la alta tasa de urbanización de nuestro país. También sucede en otros (Rotshild, Whitt, 1991). Como se señala en un importante estudio (CESB, 2002), las CTA «se concentran ya de forma prioritaria en sectores en plena expansión como son los servicios educativos, sanitarios, sociales y personales, adoptando un patrón de sociedad moderna en términos de desarrollo del tercer sector".

Las sociedades laborales, aunque existen desde los años sesenta, despegan de manera llamativa sólo desde inicios de los ochenta. Hasta mediados de los años noventa, oscilan entre 4.000 y 6.000 y, desde 1998, muestran un crecimiento espectacular, como podemos observar en el gráfico 3, de manera que llegan a 18.407 a finales de 2003. Por lo que a trabajadores se refiere, pasamos de 55.783 a finales de 1997 a 109.596 a finales de 2003.

Si las CTA son en parte una respuesta de los mismos trabajadores o de empresas autogestionadas a la crisis del empleo o, cuando menos, crecen a la sombra de esa crisis, las SAL son, en un principio, actuaciones defensivas del empleo, protagonizadas por trabajadores de empresas que entran en crisis debido a diversos procesos de reconversión. Los trabajadores compran las empresas en crisis, con sus ahorros los primeros años y posteriormente con la capitalización de las prestaciones por desempleo, contratan nuevos gestores, porque con frecuencia los antiguos se han ido con la descapitalización y los líderes sindicales de las empresas se convierten en los presidentes de las nuevas sociedades que tienen como principal capital el capital humano. Era una ruptura tal de los esquemas tradicionales al convertir al trabajador al mismo tiempo en empresario, que durante los primeros años las SAL tuvieron notables enfrentamientos con los sindicatos (CESB, 2002). Ciertamente, ese clima de tensión ha desaparecido, pero los sindicatos aún no han asimilado del todo que 


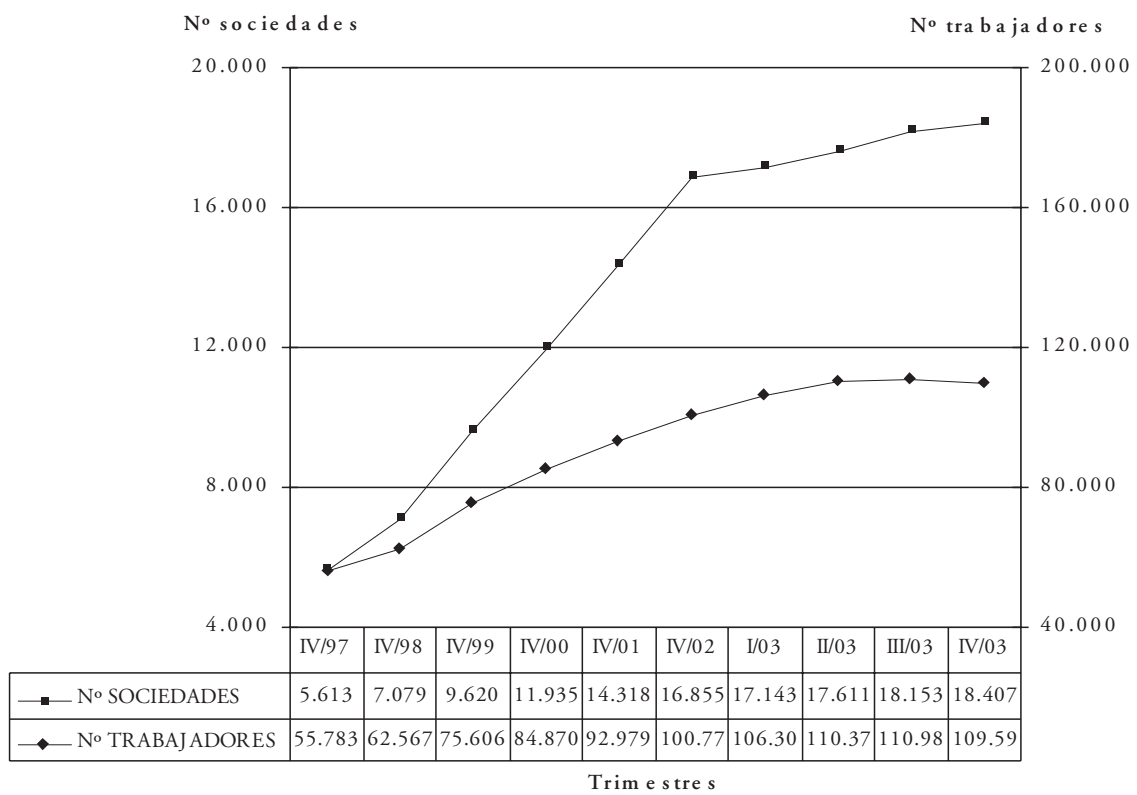

Gráfico 3. Sociedades laborales. (Fuente: Ministerio de Trabajo y Seguridad Social)

los trabajadores de las SL, si bien no tienen un patrón capitalista, sí que deben tener la integridad de los derechos laborales, igual que el resto de los trabajadores. Obviamente, los trabajadores también pueden constituir ex novo una SL si aportan el capital necesario, sin que, de por medio, deba haber una empresa en crisis cuyos empleos haya que salvar, y ésa es hoy la novedad: se crean SAL también como forma de enfrentarse a la competencia en el mercado y a veces los promotores son trabajadores altamente cualificados. Ésa es la importancia del fenómeno, que pone de manifiesto la aparición de un tipo de salarización con características especiales respecto a la tradicional.

Aquí radica una de las diferencias que se suelen dar entre estas empresas y las CTA. Las SL nacen desde abajo, están inspiradas en métodos de democracia industrial, y esto, aunque con problemas a veces, suele impregnar tanto la gestión económica como las características del empleo o las relaciones laborales.

El gran salto en la creación de SL viene provocado por la Ley de 1997 y por la decisión de muchas administraciones locales de apoyar dichas experiencias como política eficaz de autoempleo. La ley establece que los trabajadores han de ser propietarios de, al menos, el 51\% del capital social, mientras que en el 49\% restante pueden entrar entidades públicas o bien asociaciones y entidades sin ánimo de lucro. Esto posibilita que las SL reciban un importante impulso de las administraciones como instrumentos en las políticas de empleo. 
Pero la ley también facilita la creación de estas empresas — los mínimos son tres socios y un capital social de 500.000 pesetas-, lo que permite que estas experiencias vayan mucho más allá de respuestas frente a los ciclos recesivos de la economía y sean un importante instrumento de autoempleo con características colectivas. Desde la Ley de 1997, se opta principalmente por empresas de responsabilidad limitada (SLL) en vez de sociedades anónimas (SAL), con pocos trabajadores y con el objetivo básico de autoempleo. Aquí radica otra de las diferencias con las CTA y algo que convierte las SL en un elemento importante en uno de los ámbitos actuales del empleo: el autoempleo. Es un autoempleo con connotaciones colectivas y sociales, lo que las incluye de lleno en la economía social. Hacia finales de los ochenta y principios de los noventa, las SL mantenían su presencia más alta en la industria, puesto que tenían aún aquel carácter básico de salvamento de empresas en crisis, que principalmente eran industriales. Pero, paulatinamente, el centro se va desplazando hacia los servicios, como el conjunto de la economía. A principios de 2003, el porcentaje en los servicios se acercaba al 65\%, seguido de la industria y la construcción casi igualados (17\% y 16\%). A medida que las SL son empresas nuevas, y no ya la salvaguarda de las antiguas, tiende a aparecer con más frecuencia la pequeña empresa y ubicarse en los servicios, puesto que resulta más fácil de constituir: necesita menos capital y es más fácil poner de acuerdo a poca gente. La fórmula de percepción capitalizada del seguro de desempleo, que se amplía a finales de los ochenta, agiliza en manera notable esta posibilidad. Las SL entran de lleno en el universo de la pequeña empresa. Casi el $70 \%$ de las empresas no supera los cinco trabajadores, lo que abarca un $25 \%$ del total del empleo del colectivo, mientras que las que tienen cien trabajadores y más, el 0,5\% de las empresas, engloban el $11 \%$ del empleo. También en esto podemos encontrar una diferencia con las CTA.

Igual que en el caso de las CTA, también las SL tienen un índice de supervivencia mayor que las PYME normales, como podemos deducir de comparar los datos provenientes del registro de empresas y los que provienen de la Seguridad Social. Pero muchas experiencias fracasan, y con el fracaso suman trabajadores al paro. Evidentemente, una de las razones está en la fuerte competencia que han de sufrir en un sistema de producción como el nuestro, pero hay otras razones que tienen que ver con la falta de "formación empresarial» de sus dirigentes o bien con la falta de instrumentos: de asesoramiento, técnicos, de márqueting, de representación social (entrevista con Fesalc). Las políticas públicas de empleo que apoyan a los nuevos empresarios y a sus formas asociativas (federaciones de asociaciones laborales) trabajan en la dirección de dotar a estas empresas de esa acción de fondo imprescindible, pero aún hay un largo camino que recorrer para que este tipo de empresas desempeñe un papel relevante en la economía y en el empleo. En resumen, las SL ya no son producto de actuación anticíclica, para hacer frente a la pérdida de empleo (CESB, 2002), por el contrario, se sitúan en la corriente de expansión —su presencia en los servicios y en la construcción lo avalan-, en la que compiten con las empresas de carácter tradicional. 


\section{Debemos considerar también las empresas sociales de inserción para el traba-} jo. En este caso, nos encontramos con empresas no sólo relacionadas con la crisis del empleo, sino también con los problemas de igualdad de oportunidades en referencia a grupos con dificultades especiales para acceder al mercado de trabajo o sistemáticamente excluidas del mismo: personas con fracaso escolar, discapacitados físicos y mentales, drogodependientes, ex presos, etcétera. Se trata, por tanto, de empresas que buscan solucionar los problemas de las personas que tienen una difícil integración profesional y social. $\mathrm{Al}$ inicio, algunos de los promotores de este tipo de empresas han sido las comunidades cristianas de base $\mathrm{o}$ asociaciones territoriales, y la fórmula jurídica adoptada ha sólido ser la asociación o la fundación. En los últimos años, han podido gozar de mayores apoyos gracias a la Estrategia Europea para la Inclusión Social y su repercusión en los planes nacionales de empleo y al apoyo de los ayuntamientos.

Estas empresas suelen tener un carácter transitorio, puesto que su objetivo es lograr insertar a sus trabajadores en el mercado de trabajo estándar después de un cierto tiempo en el que aquéllos han adquirido experiencia, conocimientos y un currículum que les permite presentarse o ser presentados a otras empresas (CESB, 2002). Uno de los países que más ha desarrollado esta modalidad, que califican de cooperativismo social, es Italia, gracias a una ley de 1991 que favorece su constitución por medio del pago de menos impuestos y la exención de cargas sociales, con lo que se propicia el apoyo económico de la Administración (pago de salarios total o parcial en algunos casos), se les conceden créditos blandos, etcétera. Además, estas cooperativas pueden entrar en las redes del cooperativismo, lo que les da acceso a otras ventajas del asociacionismo (Inchiesta, 1999).

En España, han gozado de poco apoyo público hasta época reciente. Desde 2001, tienen el reconocimiento de «empresas de promoción e inserción social», lo que les permite constituirse con diversas fórmulas jurídicas como CTA o SAL. Los trabajadores en estas empresas reciben formación que les permite dominar un oficio o trabajar directamente en ella. Ésta se preocupa también de buscar la colocación de las personas con dificultades para encontrar trabajo por su cuenta.

En resumen, las empresas de la economía social y, específicamente, los tipos que hemos analizado en este apartado, desempeñan hoy un papel importante en las políticas públicas de empleo. Para que este objetivo se cumpla, se requiere que confluyan tres procesos. Por un lado, la existencia de colectivos de personas que quieran colaborar autogestionariamente, con finalidades sociales, lo que implica la existencia de valores asociativos que en nuestra sociedad tienen que enfrentarse con un individualismo creciente que no sólo se cierra en sí mismo, sino que suele mirar con desconfianza cualquier actuación que tenga otros horizontes. Por supuesto que los riesgos del individualismo y la tentación de aprovecharse de los demás pueden estar presentes, y lo están, también en estas empresas. Por otro lado, se requiere el apoyo de la Administración, que no sólo debe traducirse en normativas adecuadas para que esas experiencias puedan desarrollarse y en apoyo financiero que las fortalezcan — que hoy es escaso-, sino 
también en potenciar el asociacionismo al que nos referíamos, lo que no siempre ha sido el caso al menos en forma decidida. Finalmente, la educación, los medios de comunicación, la simbología pública son elementos que pueden fortalecer lo colectivo y, en consecuencia, la economía social. Aunque conviviendo con el capitalismo, este tipo de empresas tienen unos principios que difieren bastante de ese modelo económico-social, por lo cual su vida es difícil, a menos que la Administración mantenga posiciones claramente pro economía social.

\subsection{Cómo pasar de las necesidades a los empleos o la financiación de la economía social}

Partiendo de la base de que existen muchas viejas y nuevas necesidades que podrán ser cubiertas con productos o servicios realizados por la economía social, lo que generará empleos y, por tanto, bienestar para muchas personas, los problemas que se plantean son de dos tipos: ¿cómo lograr que esas empresas puedan competir con otras en el mercado?, ¿cómo conseguir una sólida demanda de esos productos o servicios que responda a las nuevas necesidades? En ambos casos, la principal respuesta está en el impulso que a la economía social da la Administración a sus diferentes niveles. En esto radica, como señalábamos al principio, que hoy se pueda hablar de tercer sector como algo distinto del sector privado y del sector público, pero más cercano a éste. Vamos a analizar brevemente esta cuestión desde un doble punto de vista: el de la oferta y el de la demanda.

En las políticas dirigidas a potenciar la oferta, cabe tener en cuenta la legislación de apoyo a la economía social y las medidas de institucionalización de la misma, como hemos visto en páginas anteriores. Tal como ha pasado en otros países, también España ha evolucionado en el sentido favorable a la economía social. De gran importancia son las políticas económicas. En primer lugar, cabe hablar de presupuestos públicos de promoción de la economía social en general, así como de contribución con financiación pública a programas concretos presentados por estas empresas. Esto explica la importante creación de CTA en las regiones de objetivo 1, cubriéndose durante un tiempo los costes laborales con recursos públicos. En las regiones de objetivo 3, se ha dado una ayuda indirecta a través de la formación. Otro tipo de ayuda indirecta, aunque no muy relevante por ahora, es el apoyo en forma de servicios: formación, asesoramiento, investigación puestos al alcance de estas empresas. De acuerdo con la clasificación presentada por Barea (Barea, 2002), podemos constatar tres tipos de medidas de apoyo:

- Las que crean o estabilizan el empleo: creándolo directamente (en actividades de interés general), apoyando el autoempleo o beneficiando la condición de socio.

- Las relativas a la formación que permiten potenciar recursos humanos: específica para ES o para la inserción.

- Otras: relativas a orientación y asesoramiento. 
El Fondo Social Europeo ha desempeñado un importante papel, pero resultaría más importante la institucionalización y la consolidación social que, derivada de las políticas — españolas y europeas-, así como del reconocimiento institucional explícito, se pudieran dar en el futuro.

Pero es en las politicas dirigidas a potenciar la demanda donde encontraríamos principalmente la clave de la estabilidad y el desarrollo de la ES. Hemos hablado anteriormente de las nuevas necesidades. Éstas podrían ser expresadas por mucha gente, pero no necesariamente transformarse en servicios, si no hay recursos para hacerles frente. Por ello cabe hablar de los nuevos aspectos del Estado de bienestar y de las nuevas formas de conseguirlo. Es precisamente ahí donde la economía social podría ser una pieza del nuevo Estado de bienestar. Sería un bienestar redimensionado en función de la escasez actual de recursos públicos —derivada principalmente del importante incremento de usuarios que trae la universalización, aunque también de los recortes en los modelos de fiscalidad-y que puede redefinir de otra manera los servicios universales, por ejemplo, en función de los ingresos. La economía social podrá ofrecer unos servicios de bienestar a menor coste que la empresa privada, al tener otra estructura de la propiedad y de la gestión y, por tanto, otra concepción de los beneficios, lo que justificaría que la Administración la apoyara y, de esa manera, la asociara a la actividad de ofrecer servicios de bienestar colectivo.

La demanda solvente puede ser privada o pública (Lope, Recio, 2004). En el ámbito estrictamente privado, ya hace años que algunas personas solucionan sus «nuevas necesidades» pagándose servicios personales y de proximidad o servicios culturales o servicios de ocio y muchos otros. Pero, tradicionalmente, estas personas han sido pocas. Cuando las administraciones han asumido que esas necesidades son generales y la sociedad debe contribuir a hacerles frente, la demanda privada ha podido recibir una subvención pública. La fórmula que ha funcionado en ciertos ámbitos como los servicios domiciliarios ha sido el «bono servicios» (o «cheque servicios»). El ciudadano que tiene esas necesidades recibe una cantidad estimada del coste de los servicios y se dirige a las empresas, las cuales pueden ser del ámbito privado o de la economía social, aunque ésta última podría ofrecer la misma calidad a menor costo, como señalábamos anteriormente. Hemos tenido diversos ejemplos de este tipo, algunos de los cuales, después de unos años, han evolucionado hacia un «cheque servicios» no universal, sino corregido por el nivel de renta: aquéllos de rentas bajas reciben el «cheque servicios» íntegro, los de renta alta no reciben dicho cheque y en las rentas intermedias existen "cheques servicios» parciales. En este nivel intermedio es presumible que muchas personas, después de haber recibido el cheque gratuitamente durante un periodo, estén dispuestas a realizar una financiación parcial. Pero muchos expertos critican esta fórmula, porque dificulta el mínimo control que quien da el dinero, la Administración, debería ejercer, tanto sobre la calidad del servicio como sobre las condiciones de trabajo de quienes lo realizan.

Cuando la demanda solvente es pública, ello quiere decir que la Administración asume cubrir esas necesidades con servicios que ofrece la Adminis- 
tración para todos. Esto puede ser realizado por dos vías: por la primera, la Administración las cubre con personal contratado por ella misma, mientras que, por la segunda, subcontrata dichos servicios a empresas, modalidad que se está generalizando en muchos países. Éstas pueden ser del ámbito privado o de la economía social y podría darse una opción preferente por ésta última por dos tipos de razones, primera, porque, al no ser empresas con ánimo de lucro particularista, sus servicios son más baratos, segunda, porque, por su estructura interna, puede acomodarse mejor a las necesidades de cada ciudadano, lo que redunda en la calidad. Pero la realidad es otra, porque las administraciones tienden a ahorrar. Dedican pocos recursos a estas contrataciones externas y, con frecuencia, las otorgan a grandes empresas porque presentan condiciones económicas más baratas. Luego estas grandes subcontratan a las pequeñas de la economía social. Parece obvio que habría que conseguir una mejora de las tarifas públicas que las empresas reciben por los servicios que prestan y al tiempo debería haber una política más decidida en pro de la economía social.

España aún queda lejos de los apoyos que la economía social tiene en otros países, tal como se puede observar en el cuadro adjunto referido a un tipo de servicios: los servicios domiciliarios (Navarro y otros, 2001).

Como podemos verificar, el grado de cobertura difiere bastante por países. Pero más importante aún es ver desde dónde se lleva a cabo la provisión del servicio. Sólo en algunos países esta provisión es directa. En la mayoría se da

Asistencia domiciliaria en Dinamarca, Suecia, Finlandia, Países Bajos, Reino Unido, Francia y Alemania. Año 2000

\section{Población potencialmente asistida}

Toda con más de sesenta y cinco años, excepto Francia y Alemania (aquí es sólo población con pocos recursos)

Grado efectivo de cobertura

Máximo: Dinamarca 24\%

Mínimo: Alemania 3\%

Personal por cada 100 usuarios

Máximo: Holanda 28

Mínimo: Reino Unido 13

\section{Servicios cubiertos}

Atenciones a las personas y a la casa.

Provisión del servicio

Municipal, tercer sector, concertado.

\section{Financiación}

Pública: Dinamarca.

Cofinanciado: Suecia, Finlandia.

No consta: resto. 
basándose en una concertación con empresas privadas y del tercer sector. El financiamiento es totalmente público sólo en Dinamarca, en algunos otros países se cofinancia. No existen datos comparables sobre España en dicho estudio, pero estamos colocados bastante por debajo de la media en gasto social de todo tipo con relación al PIB, si comparamos el conjunto de la Unión-15. Así, en el año 2001, España dedica a dicho gasto el 20,1\% del PIB, siendo la media de la UE-15 del 27,3\%. Específicamente, a la invalidez se dedica en España el 1,5\%, contra el 2,1\% en la UE; a la vejez, el 8,3\%, contra el 10,9\%; a la familia, el $0,5 \%$ contra el 2,1\% (Maravall, 2003). Por supuesto, el menor gasto dedicado a estos ámbitos repercute en menor desarrollo de la economía social. Por tanto, ahí radica una de las razones de que el porcentaje de población ocupada en la economía social sea menor, por más que los problemas de diversidad de las fuentes dificultan esta comparación. Pero también es posible que, por lo mismo, la calidad de los servicios sea menor y las condiciones de quienes trabajan sean peores.

Un capítulo de gran importancia, al efecto, es el voluntariado. Una parte del trabajo que realizan las asociaciones y las fundaciones, o bien las CTA y las empresas de inserción social, puede ser cubierta por voluntarios, si se trata de servicios a las personas o a intereses de tipo general (solidaridad con otros países, medicina, desarrollo, proyectos agrarios, de educación, etc. en el Tercer Mundo). Muchas personas pueden disponer de algunas horas al día o a la semana que quieran dedicar a los demás, a través de esas formas asociativas. Esto potencia la capacidad de actuación y de buen servicio de estas instituciones, sin que de ello resulten costes laborales, pudiéndose concentrar éstos últimos en los trabajadores no voluntarios. Pero conviene diferenciar el verdadero voluntariado del voluntariado falso, muy cercano al trabajo negro, del que empresas teóricamente sin ánimo de lucro, pero también sin escrúpulos, se podrían aprovechar.

\section{Contra el riesgo de "guetización" del empleo en el tercer sector}

Uno de los riesgos que muchos autores apuntan se refiere a que el empleo en la economía social tiende a ser de baja calidad: mal pagado, inestable, poco cualificado, con escasa consideración social, en malas condiciones (de horarios y jornada, de salud y seguridad física), en particular en el capítulo de las CTA. Si esta hipótesis fuese consistente, significaría que, ante la crisis del empleo tradicional, la economía social reacciona creando empleo pero de las mismas características que el empleo precario que crean las empresas del sector privado. Obviamente, aunque se pudiera pensar que es mejor un mal empleo que ningún empleo, parece obvio que el mal empleo no desempeña aquella clara función de motor del bienestar de las décadas precedentes, lo que introduciría dudas de que la economía social vaya en la dirección de potenciar un bienestar consistente.

Respecto a la estabilidad del empleo en este sector, una primera aproximación, basada en algunas investigaciones y en estadísticas oficiales, nos dibuja un escenario poco esperanzador. El Libro Blanco de la economía social en 
España (Barea y Monzón, 1992) señalaba que el empleo creado en las empresas de trabajo asociado a principios de los noventa era de menos precariedad que el del conjunto del sistema: un $17 \%$ de temporalidad en el primero contra un $32 \%$ en el segundo. Más recientemente, un estudio para el Libro Blanco de la economía social en la Comunidad de Valencia (Carpi y Monzón, 1998) indicaba un aumento de temporalidad en la ES, aunque aún diez puntos por debajo de la economía general, lo que la ponía al nivel de precarización que tiene lugar en el sector público. Pero los datos del Ministerio de Trabajo y Seguridad Social para diciembre de 2003 cifran en un 30,4\% la tasa de temporalidad de la economía social, es decir, exactamente igual que en la economía general. Por tanto, también la ES ha echado mano de los mismos mecanismos de ajuste y flexibilización de las empresas privadas lucrativas. Si recurrimos a investigaciones concretas sobre el tema, podemos señalar que son frecuentes los contratos temporales y por obra y servicio, con frecuencia a tiempo parcial (Lope, Recio, 2004).

En general, el peligro de "guetización» es subrayado también en la bibliografía internacional (Favreau, 2000), donde se señala en algunos países que empresas de la ES, como cooperativas, pueden subsistir sobre la base del trabajo negro (Inchiesta, 1999), lo que demuestra que tal peligro puede ser bien real, no sólo en nuestro país. Por ello, una primera conclusión es que la economía social puede deber su crecimiento de los últimos diez años en parte a la utilización de la misma estrategia de flexibilidad que la empresa privada, lo que probablemente le permite resistir la competencia, pero a costa de la inseguridad en el empleo y de la calidad de los servicios prestados. Pero esta posible conclusión podría ser relativizada, por cuanto la inseguridad jurídica expresada en la temporalidad no necesariamente implica malas condiciones de trabajo. Por ello, conviene dar un paso más en esta investigación, para lo cual nos vamos a referir a los salarios pagados en la ES en comparación con los que se perciben en la economía general, pero también a las calificaciones y a la jornada laboral. Cabe decir que la información con la que contamos no es muy abundante y, además, convendría diferenciar entre sectores para tener una visión más precisa.

El primer aspecto a considerar son los salarios. A través de investigaciones referidas a las condiciones de trabajo en los "nuevos yacimientos de empleo» - donde, obviamente, convive la empresa privada con la empresa social-, pero que son un campo abonado para la ES, podemos señalar la existencia de una doble tendencia: la de salarios bajos y la de salarios medios altos (QUIT, 1999). Predominan los salarios bajos en actividades más manuales de preservación o reparación del medio ambiente, así como en actividades no cualificadas de cuidado del patrimonio local y del turismo local (vigilantes, bedeles, camareros, limpieza). También predominan los salarios bajos en el sector de seguridad y vigilancia en general. Los servicios a domicilio, la atención a las personas mayores y a los niños no sólo tienen salarios bajos, sino poco prestigio social, derivado del hecho que esos empleos son vistos actualmente como continuación de las tareas del hogar, tradicionalmente desarrolladas por las 
mujeres. En el amplio ámbito de la limpieza, ya sea el servicio prestado a las empresas, ya sea a los particulares, también predominan los salarios bajos. En algunos de estos sectores mencionados están entrando mujeres inmigrantes extracomunitarias, y esta abundancia de oferta, sumada a la casi nula organización social colectiva, contribuye a mantener bajos los salarios. Por supuesto, en algunos de estos yacimientos, como medio ambiente, cultura y turismo, también hay empleos con salarios medios altos.

En muchos de estos nuevos sectores de actividad, como se desprende de su mera enumeración, está muy presente la economía social, la cual tiende a mantener unos salarios similares a los del sector privado, es decir, predominantemente bajos. En la investigación anteriormente señalada (Lope, Recio, 2004) sobre empresas en las que es vigente el II Convenio de empresas y trabajadores/as de atención domiciliaria y trabajo familiar de Catalunya, algunos ejemplos de salarios frecuentes a finales de 2003 eran los siguientes:

\section{- Trabajadora familiar y auxiliar de geriatría a domicilio:}

$9.598 €(1.597 .100$ pts. $) /$ año.

- Auxiliar de limpieza de apoyo a domicilio:

$8.775 €(1.460 .100$ pts. $) /$ año.

Se trata de las principales categorías de trabajadoras en este tipo de empresas. Para desempeñar el segundo trabajo no se requiere formación específica y para el primero se exige titulación de «trabajadora familiar» o de «auxiliar de geriatría» (conseguidas en ciclos formativos). Otra investigación ya citada (QUIT, 1999) también señala la existencia de bajos salarios entre los trabajadores de los niveles inferiores. Una buena parte del empleo de la economía social se ubica en las franjas salariales bajas. Lo dicho hasta ahora no siempre vale para las SAL, donde los salarios no son altos, pero tampoco se ubican en las franjas más bajas. Pero conviene buscar las razones de esos bajos salarios. Cuando se trata de empresas que realizan servicios personales financiados totalmente o en parte por la Administración, la razón principal puede estar en los escasos recursos públicos dedicados a esos servicios. En el caso de las SAL, la razón puede ser que se trata de empresas de baja productividad en términos comparativos.

Suelen tener calificaciones bajas muchos de los empleos de servicios a las personas y de servicios de proximidad debido a un doble motivo: a que la consideración social que reciben es baja y a que la tecnología y la complejidad incorporada es escasa. Incrementar la consideración social implica cambios culturales de gran importancia que son viables a largo plazo, y también otros cambios institucionales, como el organizar estudios reglados al respecto, que tendrían efectos a más corto plazo. Pero hay posibilidades de recalificación a más corto plazo, a través de procesos de polivalencia y tecnificación. Por ejemplo, muchos servicios de proximidad podrían incorporar actuaciones que requieren conocimientos de psicología y enfermería. Las actividades más manuales de medio ambiente podrían incorporar una actuación y unos conocimientos globales de todo el proceso. En la limpieza, la recalificación podría venir de la 
mano de una mayor mecanización de los procesos (Quit, 1999). Con todo, parece obvio que muchos de los empleos son de difícil recalificación. También, por lo que se refiere a este aspecto, en las SAL buena parte de los socios empleados no sólo pueden tener calificación relativamente buena, sino que se observa un incremento de las mismas en el último tiempo (Fesalc, sin fecha). La propia Comisión Europea lo entiende así al señalar que «habrá que establecer un marco profesional adecuado con el fin de revalorizar las competencias y dar a conocer los nuevos oficios [...] pensando en nuevos títulos profesionales» (Comisión Europea, 1995). Con todo, habría que señalar que la formación por sí sola no puede arreglar las cosas, si sigue habiendo una segregación por género y los salarios son tan bajos.

Por lo que respecta a las horas de trabajo, nos encontramos con una doble realidad. En ciertos subsectores de la ES, los horarios pueden ser los normales, pero la existencia de horas extras fácilmente los pueden alargar. Es el caso de las SAL, que pueden tener en eso un instrumento de competitividad. En otros, por ejemplo en los servicios a domicilio, tienden a ser abundantes las jornadas a tiempo parcial —a veces también con horas extras-, lo que facilita la incorporación de mujeres que mantienen el trabajo doméstico en sus propias casas. Pero los horarios parciales para "compatibilizar con las propias obligaciones» se convierte en un obstáculo más para la profesionalización en ese trabajo.

Algunas reflexiones generales respecto a este apartado. La ES, siguiendo los pasos de la empresa privada tradicional y del ámbito público, ha potenciado una fuerte segmentación del mercado de trabajo, utilizando la misma estrategia de flexibilidad para hacer frente a la competencia que las otras empresas. Por lo que respecta a las CTA, particularmente aquéllas que trabajan en servicios personales, el deterioro del empleo es básicamente atribuible a la escasa financiación con la que la Administración hace frente a estas necesidades y al poco control que ésta tiene de la calidad del servicio, que, en muchos casos, debería ser básicamente calidad de los recursos humanos, cuando adjudica los contratos.

\section{5. ¿Regular las relaciones laborales en el tercer sector?}

Una conclusión que se deriva de diversas investigaciones es que el empleo está poco regulado y las normas son poco cumplidas en este ámbito en el que las relaciones laborales pueden estar basadas en la falta de interlocutores sociales organizados, en el subjetivismo y, por tanto, en un cierto grado de arbitrariedad. Sin embargo, parece obvio que en nuestra sociedad los trabajadores de la economía social deban exigir la plenitud de los derechos laborales. En principio, no repartir beneficios, sino reinvertirlos, es un modo de potenciar los servicios sociales, la sociedad civil y el bienestar, pero ese bienestar no se puede basar en el malestar de quienes trabajan con menos derechos (Cangiani, 1999).

Es necesario pensar que, cuando se habla de derechos de los trabajadores, la referencia no se hace únicamente a los salarios — que en ciertas tareas podrían 
ser tan bajos como en esos mismos sectores de la economía privada-, sino también a la calificación, a la formación y promoción, a horarios que permitan conciliar la vida laboral con la personal y familiar, a la salvaguarda en la enfermedad, a la jubilación. En muchos de estos sectores la mejora del empleo y de las condiciones de trabajo debería pasar por potenciar sus recursos humanos: desarrollar nuevos ámbitos formativos, facilitar la formación continua a estos trabajadores, posibilitar algún tipo de promoción son medidas que consolidarían estos empleos.

El tipo de regulación normativa es, obviamente, el mismo que tiene lugar en la economía general. Me refiero a salarios, jornadas, derechos sociales, pero la indefinición de estos empleos y de estas empresas provoca que, con frecuencia, no haya vigilancia suficiente para hacer frente a los abusos que se puedan producir. Hasta puede parecer fuera de lugar que intervengan los sindicatos o la inspección con dicha finalidad. Un aspecto de gran trascendencia es que CTA y SAL parecen tener con mucha frecuencia más empleados no socios de lo que permite la ley, los cuales no denuncian su situación por no perder el empleo. Inestabilidad, por tanto, similar a la de las empresas privadas.

La que podríamos llamar regulación social adquiere dos modalidades: la regulación vía convenio y la que tiene lugar a través de la concertación. La regulación por la vía del convenio implica la existencia de unas relaciones laborales consistentes y autónomas. En algunos subsectores, existen convenios laborales territoriales, aunque con frecuencia los interlocutores, particularmente por parte de los trabajadores, son débiles o inexistentes y, sin embargo, la mayoría de los trabajadores se rigen por los respectivos convenios de sector, en cuya negociación ni intervienen los trabajadores ni las empresas de la ES. En algún país (Italia), se han desarrollado convenios marco, por ejemplo de cooperativas o de cooperativas de trabajo asociado. Un convenio marco podría reconocer a los trabajadores de la ES todos los derechos que tienen los demás trabajadores. Podría poner el acento sobre la reducción de la precariedad, aunque fuera de manera progresiva. Debería buscar la valoración del trabajo social y potenciar su profesionalidad: fijando categorías vinculadas a grados de responsabilidad, definiendo competencias en relación con niveles de formación. Sobre todo, tendría más capacidad para exigir a la Administración condiciones económicas y normativas adecuadas para contratar con la ES. Aunque hay quien cree que ese camino les separaría aún más del resto de los trabajadores.

Probablemente, la solución no es imaginar que el trabajo en cooperativas y empresas de trabajo asociado es exactamente igual al trabajo dependiente, pero tampoco suponer que ahí no podemos hablar de relaciones laborales y de derechos (Rodríguez Piñero, Puy Fernández, 2003). Se trata de preservar los valores del trabajo asociado: relación personal, solidaridad, autogestión de la propia empresa. Por ello, un convenio marco debería también desarrollar y regular la originalidad de la relación del trabajo cooperativo y asociado. Pero a continuación debería definir retribuciones mínimas, en relación con el sector de actividad del que se trate, señalar jornadas y días de descanso (un problema 
muy grave en los servicios domiciliarios), vacaciones y todos los demás aspectos que sean necesarios.

Imprescindible es que la organización de los trabajadores en el sector, seguramente debería tener aspectos particulares, puesto que su contraparte no es un patrón privado, lo que debería implicar un fuerte desarrollo de formas participativas de los trabajadores en el funcionamiento de las empresas. Por lo que respecta a éstas, la consolidación de asociaciones y de federaciones de asociaciones - asociaciones de segundo nivel — garantizaría un actor social potente que no buscaría el beneficio, sino desempeñar un papel importante en la sociedad civil y en el bienestar, pero sobre la base del respeto a los derechos laborales.

Lo que actualmente sucede es que, aún en los casos en los que formalmente existe una regulación, la debilidad organizativa de los trabajadores o bien la indecisión de la Administración puede convertir la regulación en papel mojado. En general, cabe señalar que, en ámbitos como el de servicios a domicilio, la regulación de las condiciones de trabajo es escasa y confusa (Lope, Recio, 2004). El convenio vigente en este sector "obliga» a incrementar el empleo estable ("para el 2004, al menos el 34\% de las plantillas de las empresas habrán de contar con contrato indefinido»). El que está vigente en las residencias privadas señala que "para finales de 2003, el $45 \%$ de las plantillas deberán tener contrato indefinido, porcentaje que subirá al $60 \%$ a finales de 2004». La realidad está muy alejada de esto en las empresas analizadas en el estudio señalado, y también en muchas otras, a pesar de que las administraciones públicas, que son quienes realizan las concesiones de los servicios, podrían exigir ese cumplimiento como un requisito en el momento del concurso. Se podría decir más: la Administración podría exigir que las empresas con las que contrata esos servicios mantuviesen determinadas condiciones de trabajo o bien podría poner cláusulas adecuadas de subcontratación en el caso de contratar a empresas grandes. Tratándose de dinero público, no parece inadecuado ese control.

Pero también es posible establecer la regulación a través de la concertación. La actividad de estas empresas suele cubrir un área local, dado que están ubicadas en dicho territorio, responden a necesidades locales y es la Administración local la que aporta una buena parte de los recursos de los que se nutren. Es, por tanto, posible que se genere una dinámica en la que los protagonistas locales, sobre la base de la concertación, den un fuerte impulso a la ES. Es conocido el caso de Québec (Favreau, 2000), donde las 5.000 empresas de ES de la zona en el año 2000, en diversos sectores de los servicios (servicios personales) e industrial (maderero), se han consolidado en redes de asociaciones, han crecido gracias a la existencia de fondos de desarrollo (capital local, ciudadanos, capital sindical, capital público) y han posibilitado la creación de empleo de mayor calidad, superando también importantes subordinaciones de género. Específicamente, las empresas de inserción cumplen un papel básico de integración social. 


\section{Conclusión: economía social y bienestar}

Parecen fuera de lugar ciertas consideraciones sobre el tercer sector en el sentido de que éste estuviese llamado a sustituir al Estado en sus funciones de bienestar. Podemos pensar más en la línea de la complementación. La reestructuración del Estado de bienestar que está teniendo lugar, apunta a una redefinición de la economía mixta en la que lo público estatal retrocede a favor de lo privado mercantil y de lo privado social. Lo que está teniendo lugar es un «adelgazamiento» del Estado como proveedor de servicios que se canalizan al privado mercantil y al social, creando mercados internos de servicios públicos, apoyando la elección de servicios (enseñanza), conteniendo el gasto social mediante la reducción de la intensidad protectora (Rodríguez Cabrero, 2000). Así están las cosas, pero el debate es en qué grado se hayan de crear esos mercados internos — puede haber servicios esenciales que preservar-y sobre todo qué supone, para ciertos colectivos, que se reduzca la intensidad protectora. También está en discusión si, pagando el Estado, los servicios públicos los ofrece mejor la iniciativa privada mercantil o la social.

Parecería que la segunda opción es más coherente, siempre que la calidad ofrecida por la ES garantice los objetivos. Ésta podría ser más elástica y flexible para adaptarse a las muchas manifestaciones que tienen hoy las necesidades sociales. Esto es lo que en muchos países ha llevado al contracting out hacia la ES. Pero si la Administración busca sólo la opción más barata, corre el riesgo de que servicios y bienestar sean de baja calidad. Se requeriría algún tipo de regulación de calidad que garantice que las empresas de ES que participen tengan solvencia. Algunos de los aspectos que debería contemplar esta normativa serían: aplicar el convenio colectivo que corresponda a sus trabajadores, tener experiencia en el sector, disponer de personal titulado con calificación adecuada y contar con una plantilla adecuadamente estable (la excesiva rotación repercute negativamente sobre los servicios prestados). Pero, como contrapartida, se deberían poner a disposición recursos financieros suficientes.

En el fondo, parece que no tiene vuelta atrás la tendencia de que una parte de los servicios públicos y sociales no sea ofrecida directamente por el Estado. Lo importante no es eso, sino que sean ofrecidos universalmente, o cuando menos con garantías de apoyo según niveles de renta, lo que implica que el Estado se tiene que implicar de alguna manera con los recursos públicos. Si se consigue que una buena parte de estos servicios sea ofrecida por empresas de ES, que funcionen con calidad, transparencia y democracia, no sólo se habrá ganado en bienestar de los servicios, sino también en bienestar de la relación laboral y social.

\section{Bibliografía}

BAREA, J.; MONZÓN, J.L. (1882). Libro Blanco de la economía social. Madrid: CIRIEC. - (dir.) (2000). La economía social en España. Madrid: CIRIEC.

CACHÓN, L.; FUNDACIÓN TOMILLO (1998). Nuevos yacimientos de empleo en España:

Potencial de crecimiento y desarrollo futuro. Madrid: MTSS. 
CARPI, A.; MONZON, J.L. (1998). Libro Blanco de la economía social en el País Valenciano. Madrid: CIRIEC.

CES (2005). La temporalidad a la Administración. Madrid: Consejo Económico y Social.

Comisión Europea (1995). Proyectos piloto relativos a nuevos yacimientos de empleo. Bruselas DG XVI.

- (2003). L'emploi en Europe 2000. Bruselas.

CONSELL ECONOMIC I SOCIAL DE BARCELONA-CESB (2002). El tercer sector i l'economia social a Barcelona. Barcelona.

FAVReAU, L. (2000). Nueva economía social y empleo en Québec: Hacia una democratización de las relaciones laborales.

FESALC (sin fecha). Innovación y Trabajo. Barcelona: Fesalc.

GOMÁ, R. y otros (2001). Seminari sobre el tercer sector. Barcelona: Generalitat de Catalunya. Secretaría General de Joventut.

INCHIESTA (1999). Cooperative sociali e terzo settore. Inchiesta n. ${ }^{\circ}$ 123-124. Bolonia.

LOPE, A.; ReCIO, A.; GIBERT, F. (2004). La qualitat de l'ocupació $i$ dels serveis d'assistència domiciliària a Manlleu. Bellaterra: QUIT, UAB.

Maravall, H. (2003). Las politicas de bienestar social en España. Madrid: CCOO. POLLERT, A. (1991). Farewell to Flexibility? Londres: Basil Blackwell.

PRIETO, C. (2002). «La degradación del trabajo o la norma social del empleo flexibilizado». Sistema, n. ${ }^{\circ}$ 168-169, julio.

QUIT (2001). «Els nous filons d'ocupació. Informe sobre les condicions de treball en els diversos sectors dels nous filons d'ocupació a Catalunya». En Llibre blanc dels nous filons d'ocupació a Catalunya. Barcelona: Entitat Autònoma del Diari Oficial i de Publicacions.

Rodríguez Cabrero, G. (2000). «Economía social y Estado de bienestar». En Barea. La economía social, op. cit.

Rodríguez Piñero, M.; Puy FernándeZ, G. (2003). «Relaciones laborales y empresas de economía social». En VARIOS AUTORES. La economía social y el tercer sector.

RothsChild, J.; Allen WhitT, J.(1991). El lugar del trabajo cooperativo. Madrid: MTSS.

ToRns, T. (2004). «Las políticas del tiempo: un reto para las políticas del Estado de bienestar». Trabajo, n. ${ }^{\circ}$ 13, enero-junio. Universidad de Huelva.

Varios Autores (2002). Temps i ciutat. Consejo Económico y Social de Barcelona. VARIOS AUTORES (2003). La economía social y el tercer sector. Madrid: Escuela Libre Editorial.

VIDAL, I. (2001). Llibre Blanc de l'Economia Social a Catalunya. Centro de Investigación Ciudadanía y Sociedad Civil. Universidad de Barcelona.

VIDAL, I. y otros (2002). El tercer sector i l'economia social a Barcelona. 